\title{
Glycosylated hemoglobin A1c as a marker predicting the severity of coronary artery disease and early outcome in patients with stable angina
}

Li-Feng Hong ${ }^{1,2}$, Xiao-Lin Li ${ }^{1}$, Yuan-Lin Guo ${ }^{1}$, Song-Hui Luo ${ }^{2}$, Cheng-Gang Zhu' ${ }^{1}$, Ping Qing ${ }^{1}$, Rui-Xia Xu' Na-Qiong $\mathrm{Wu}^{1}$ and Jian-Jun $\mathrm{Li}^{1 *}$

\begin{abstract}
Background: Glycosylated hemoglobin A1C ( $\mathrm{HbA} 1 \mathrm{c})$ has been widely recognized as a marker for predicting the severity of diabetes mellitus (DM) and several cardiovascular diseases. However, whether HbA1c could predict the severity and clinical outcomes in patients with stable coronary artery disease (CAD) remains largely unknown. We determine relationship of $\mathrm{HbA} 1 \mathrm{c}$ with severity and outcome in patients with stable CAD.
\end{abstract}

Methods: We enrolled 1433 patients with stable angina who underwent coronary angiography and were followed up for an average 12 months. The patients were classified into three groups by tertiles of baseline HbA1c level (low group $<5.7 \%, n=483$; intermediate group $5.7-6.3 \%, n=512$; high group $>6.3 \%, n=438$ ). The relationships between the plasma HbA1c and severity of CAD and early clinical outcomes were evaluated.

Results: High HbA1c was associated with three-vessel disease. Area under the receivers operating characteristic curve (AUC $=0.67,95 \% \mathrm{Cl}: 0.63-0.71, \mathrm{P}<0.001)$ and multivariate logistic regression analysis suggested that HbA1C was an independent predictor of severity of $C A D(O R=1.60,95 \% \mathrm{Cl}: 1.29-1.99, \mathrm{P}<0.001)$ even after adjusting for gender, age, risk factor of CAD, lipid profile and fasting blood glucose. During follow-up, 133 patients underwent pre-specified outcomes. After adjusting for multiple variables in the Cox regression model, $\mathrm{HbA1C}$ remained to be an independent predictor of poor prognosis ( $\mathrm{HR}=1.28,95 \% \mathrm{Cl}$ : 1.12-1.45, $\mathrm{P}<0.001)$.

Conclusions: We concluded that high level of baseline HbA1c appeared to be an independent predictor for the severity of CAD and poor outcome in patients with stable CAD.

Keywords: Hemoglobin A1c, Stable angina pectoris, Coronary artery disease, Outcome

\section{Introduction}

Glycosylated Hemoglobin A1c (HbA1c) is a pivotal biomarker reflecting both fasting and postprandial plasma glucose concentration over the preceding 2-3 months $[1,2]$. And also, it has been regarded as an important tool in diabetes diagnosis and management [1-5]. It has been reported that elevated HbA1c levels probably mean longterm insulin resistance and severe consequences such as hyperglycemia, dyslipidemia, hypercoagulability, and system inflammatory response [5-7]. Furthermore, several

\footnotetext{
* Correspondence: lijianjun938@yahoo.com

'Division of Dyslipidemia, State Key Laboratory of Cardiovascular Disease, Fu Wai Hospital, National Center for Cardiovascular Diseases, Chinese Academy of Medical Sciences, Peking Union Medical College, Beijing 100037, China Full list of author information is available at the end of the article
}

studies have demonstrated a positive relationship between elevated HbA1c and poor outcome in the setting of general population, acute coronary syndrome (ACS), acute myocardial infarction (AMI), heart failure, pancreatitis, and even patients after coronary artery bypass surgery and drug-eluting stent (DES) implantation with and without primary diabetes mellitus (DM) [8-17]. Although consistent evidences have supported that optimal control of HbA1c at a target value can confer to a lower incidence of microvascular complications both in type 1 and type 2 DM, the association of high levels of HbAlc with macrovascular disease such as stable coronary disease remains controversial [11,12,18-21].

Moreover, a few population studies suggested that the values of plasma HbAlc should be perceived as a 
continuous variable without a normal cut-off point because it might exhibit a significantly detrimental role even when it was in "normal" or relatively low levels [6,7]. More interestingly, it has also been showed that a higher level of circulating $\mathrm{HbA1c}$ was related to elevated inflammatory markers such as C-reactive protein (CRP), fibrinogen and white blood cell count, which were routinely available and well established predictors of future mortality. Therefore, it might provide meaningfully predictive value than either alone [6,7]. Meanwhile, several previous studies have demonstrated a positive correlation of high $\mathrm{HbA1c}$ levels with severity of coronary artery disease while the clinical significance of previous observation were apparently limited by either a retrospective design manner or small sample size [22-26]. According to the best of our knowledge, data from larger sample in a prospective design regarding the value of plasma $\mathrm{HbA1c}$ in predicting the disease severity in patients with stable coronary artery disease (CAD) is not currently available. Furthermore, whether the elevated HbA1c levels could also provide any additional prognostic information for those patients with stable CAD remains to be determined.

The aim of this study, therefore, was to prospectively investigate the predictive power of HbA1c levels for the severity and the early outcome in patients with stable CAD.

\section{Materials and methods}

\section{Study population}

This was a single center, prospective follow-up study. From June 2011 through March 2012, we prospectively enrolled 1433 consecutive women and men (70.3\%) aged 19 to 86 years (average age 58.29 years) with typical stable exertional angina pectoris referred for selective coronary angiography at our center. Patients with ACS, significant hematologic disorders (white cell count $<3.5 \times 10^{9} / \mathrm{L}$ or $>20 \times 10^{9} / \mathrm{L}$ ), infectious or inflammatory disease, severe liver and/or renal insufficiency were excluded from the present study. Data including the demographic, clinical, laboratory findings and angiographic examination were collected from all patients.

The protocol of this study was approved by Fu Wai hospital ethics committee, and complied with the Declaration of Helsinki. The informed consent was obtained from all participants.

\section{Diagnostic criteria}

Hypertension was defined by SBP $\geq 140 \mathrm{mmHg}$ and/or $\mathrm{DBP} \geq 90 \mathrm{mmHg}$, or currently receiving antihypertensive medication [27]. The diagnostic criteria recommended by WHO for diabetes mellitus were used [28]. According to these criteria, we diagnosed patients as having diabetes with fasting blood glucose values $\geq 126 \mathrm{mg} / \mathrm{dl}$, or 2 -h blood glucose $\geq 200 \mathrm{mg} / \mathrm{dl}$, or under the active treatment with insulin or oral hypoglycemic agents.
Hyperlipidemia was considered to be present in patients with fasting total cholesterol (TC) $\geq 200 \mathrm{mg} / \mathrm{dl}$ or triglyceride (TG) $\geq 150 \mathrm{mg} / \mathrm{dl}$. CAD was defined as the presence of significant obstructive stenosis at least $50 \%$ of the vessel lumen diameters in any of the main coronary arteries by at least two independent senior interventional cardiologists based on quantity coronary angiography. The severity of CAD was scored as 0 (absent or minimal atherosclerotic involvement), 1 (single vessel disease), 2 (two-vessel disease), 3 (three-vessel disease and/or left main stem disease and/or equally affected of left anterior descending and left circumflex branch). The left ventricular ejection fraction was evaluated by echocardiograph using the area-length methods or modified Simpson's rule.

\section{Biochemical examination}

Venous blood samples were obtained from each patient at baseline on admission. HbA1c levels were measured using the Tosoh G7 Automate HPLC Analyzer (TOSOH Bioscience, Japan). The concentrations of high-sensitivity C-reactive protein (hs-CRP) were determined using immunoturbidimetry (Beckmann Assay 360, Bera, Calif., USA). TC and TG were measured by enzymatic methods and high-density lipoprotein cholesterol by a direct method (Roche Diagnostics, Basel, Switzerland). Low-density lipoprotein cholesterol was obtained by Friedewald's formula (if fasting triglycerides $<3.39 \mathrm{mmol} / \mathrm{l}$ ) or by ultracentrifugation. Apolipoprotein $\mathrm{B}$ was measured by an immune-turbidimetric method (Tina-quant, Roche Diagnostics) calibrated against the World Health Organization/ International Federation of Clinical Chemistry reference standard SP3-07. All other included biomarkers were analyzed by standard hematological and biochemical tests.

\section{Follow up}

All patients were subjected to follow up throughout the study period with an average of 12 months by a telephone and/or clinical interview. The pre-specified clinical end points were defined as cardiac death, nonfatal MI, revascularization, and re-hospitalization due to attack of acute coronary syndrome (ACS).

\section{Statistical analysis}

Continuous variables and categorical variables were analyzed by the chi-squared statistic tests, the one-way analysis of variance test, or the Kruskal-Wallis test when appropriate. Receivers operating characteristic (ROC) curves were constructed at the most discriminating cutoff point values to predict CAD. The relationship of HbA1c with angiographic findings were evaluated by univariate and multivariate logistic regression models (including potential factors such as age, gender, cardiac risk factors, medicine treatment, DES implantation, baseline lipid profile and other hematological index) using forward stepwise 
Table 1 Baseline characteristics according to the tertiles of serum hemoglobin A1C levels

\begin{tabular}{|c|c|c|c|c|c|}
\hline \multirow[t]{2}{*}{ Variables } & \multicolumn{4}{|c|}{ Tertiles of serum hemoglobin A1C levels (\%) } & \multirow[t]{2}{*}{ P-value } \\
\hline & Total $(n=1433)$ & Low $(<5.7 ; n=483)$ & $\begin{array}{l}\text { Intermediate } \\
(5.7 \sim 6.3 ; \mathrm{n}=512)\end{array}$ & High $(>6.3 ; n=438)$ & \\
\hline \multicolumn{6}{|l|}{ Demographic } \\
\hline Age, years & $58.3 \pm 10.2$ & $55.5 \pm 10.8$ & $59.6 \pm 9.6$ & $59.8 \pm 9.5$ & $<0.001$ \\
\hline Male gender & 1008(69.9) & $365(75.6)$ & $350(68.3)$ & 293(66.9) & 0.008 \\
\hline Risk factors Body mass index $\left(\mathrm{kg} / \mathrm{m}^{2}\right)$ & $25.5 \pm 3.2$ & $25.0 \pm 3.0$ & $25.4 \pm 3.3$ & $26.0 \pm 3.2$ & $<0.001$ \\
\hline Current Smoking & $770(53.4)$ & $271(56.1)$ & $272(53.1)$ & 227(51.8) & 0.404 \\
\hline Hypertension & $909(63.4)$ & $280(58.0)$ & $317(61.9)$ & $312(71.2)$ & $<0.001$ \\
\hline Diabetes mellitus & $374(26.1)$ & 89(18.4) & $93(18.2)$ & 192(43.8) & $<0.001$ \\
\hline Hyperlipidemia & 1064(74.2) & $306(63.4)$ & $393(76.8)$ & 365(83.3) & $<0.001$ \\
\hline Peripheral vascular disease & $26(1.8)$ & $6(1.2)$ & $11(2.1)$ & $9(2.1)$ & 0.509 \\
\hline Prior Stroke & $68(4.7)$ & $16(3.3)$ & $27(5.3)$ & $25(5.7)$ & 0.182 \\
\hline Family history of CAD & 158(11.0) & $44(9.1)$ & $55(10.7)$ & 59(13.5) & 0.104 \\
\hline \multicolumn{6}{|l|}{ Laboratory date } \\
\hline LVEF (\%) & $62.2 \pm 8.1$ & $62.5 \pm 8.2$ & $62.1 \pm 8.2$ & $62.2 \pm 7.9$ & 0.672 \\
\hline NT-pro-BNP (fmol/mL) & $710.4 \pm 515.7$ & $663.9 \pm 422.7$ & $720.8 \pm 492.3$ & $749.5 \pm 622.1$ & 0.036 \\
\hline $\mathrm{FBG}(\mathrm{mmol} / \mathrm{L})$ & $5.5 \pm 1.5$ & $6.8 \pm 2.1$ & $5.0 \pm 0.6$ & $4.7 \pm 0.6$ & $<0.001$ \\
\hline Haemoglobin (g/L) & $139.9 \pm 15.1$ & $141.5 \pm 14.9$ & $139.7 \pm 14.7$ & $138.3 \pm 15.9$ & 0.006 \\
\hline Leucocyte count $\left(10^{9} / \mathrm{L}\right)$ & $6.4 \pm 1.6$ & $6.2 \pm 1.6$ & $6.4 \pm 1.6$ & $6.6 \pm 1.7$ & 0.002 \\
\hline Platelet count (109/L) & $205.1 \pm 60.7$ & $201.8 \pm 68.6$ & $208.4 \pm 58.6$ & $204.9 \pm 53.7$ & 0.221 \\
\hline Fibrinogen (g/L) & $3.2 \pm 0.8$ & $2.9 \pm 0.6$ & $3.2 \pm 0.7$ & $3.3 \pm 0.9$ & $<0.001$ \\
\hline D-dimer (mg/dL) & $0.4 \pm 0.7$ & $0.3 \pm 0.4$ & $0.4 \pm 0.6$ & $0.3 \pm 1.0$ & 0.023 \\
\hline hs-CRP (mg/L) & $2.9 \pm 3.6$ & $2.1 \pm 2.9$ & $3.0 \pm 3.5$ & $3.6 \pm 4.1$ & $<0.001$ \\
\hline Endothelin-1 (fmol/mL) & $0.6 \pm 0.3$ & $0.6 \pm 0.3$ & $0.6 \pm 0.3$ & $0.6 \pm 0.3$ & 0.492 \\
\hline Albumin $(\mathrm{g} / \mathrm{L})$ & $41.8 \pm 3.5$ & $41.6 \pm 3.3$ & $41.9 \pm 3.8$ & $41.8 \pm 3.4$ & 0.491 \\
\hline $\mathrm{Cr}$ (umol/L) & $75.6 \pm 16.2$ & $75.4 \pm 13.8$ & $75.4 \pm 17.1$ & $76.2 \pm 17.5$ & 0.686 \\
\hline UA (mmol/L) & $347.4 \pm 4.2$ & $354.0 \pm 83.3$ & $348.8 \pm 80.5$ & $338.5 \pm 88.8$ & 0.017 \\
\hline \multicolumn{6}{|l|}{ Lipid profile } \\
\hline Triglycerides (mmol/L) & $4.2 \pm 1.1$ & $4.1 \pm 0.9$ & $4.2 \pm 1.1$ & $4.1 \pm 1.1$ & 0.008 \\
\hline Total cholesterol (mmol/L) & $4.2 \pm 1.1$ & $4.0 \pm 0.9$ & $4.2 \pm 1.1$ & $4.2 \pm 1.1$ & 0.077 \\
\hline LDL-C (mmol/L) & $2.5 \pm 0.9$ & $2.5 \pm 0.9$ & $2.5 \pm 0.8$ & $2.5 \pm 0.9$ & 0.497 \\
\hline $\mathrm{HDL}-\mathrm{C}(\mathrm{mmol} / \mathrm{L})$ & $1.1 \pm 0.3$ & $1.1 \pm 0.3$ & $1.1 \pm 0.2$ & $1.1 \pm 0.3$ & 0.051 \\
\hline Lipoprotein (a) (mg/L) & $236.9 \pm 244.6$ & $220.6 \pm 224.7$ & $265.6 \pm 263.4$ & $221.4 \pm 240.4$ & 0.004 \\
\hline ApoA (g/L) & $1.5 \pm 0.3$ & $1.5 \pm 0.3$ & $1.5 \pm 0.2$ & $1.5 \pm 0.3$ & 0.920 \\
\hline ApoB (g/L) & $1.1 \pm 0.3$ & $1.0 \pm 0.3$ & $1.1 \pm 0.3$ & $1.1 \pm 0.3$ & 0.157 \\
\hline \multicolumn{6}{|l|}{ Medical treatment } \\
\hline Aspirin & 1358(94.8) & 444(91.9) & $490(95.7)$ & 424(96.8) & 0.002 \\
\hline Clopidogrel & $1297(90.5)$ & 416(86.1) & $473(92.4)$ & 408(93.2) & $<0.001$ \\
\hline Beta-blocker & $1129(78.8)$ & $351(72.7)$ & $415(81.1)$ & 363(82.9) & $<0.001$ \\
\hline ACE-I & $424(29.6)$ & 132(27.3) & 162(31.6) & 130(29.7) & 0.389 \\
\hline Statin & 1332(93.0) & 429(88.8) & 486(94.9) & 417(95.2) & $<0.001$ \\
\hline DES implantation & 250(17.4) & $60(12.4)$ & 109(21.3) & $81(18.5)$ & 0.001 \\
\hline
\end{tabular}

CAD = Coronary artery disease; LV-FE = Left ventricular ejection fraction; hs-CRP = high sensitivity C-reactive protein; LDL-C = Low density lipoprotein cholesterol; HDL-C = High density lipoprotein cholesterol; ACE-I = Angiotensin converting enzyme inhibitors; DES = Drug eluting stent. 
selection process. The association of $\mathrm{HbA1c}$ with 12month outcomes was determined with Cox proportional hazard models using forward stepwise selection process. Event-free survival curves were constructed using the Kaplan-Meier methods and compared using log-rank test. All analyses were performed using SPSS version19.0 software (Chicago, Illinois, USA).

\section{Results}

\section{Baseline characteristics}

The baseline demographic, clinical characteristics and laboratory findings according to tertiles of HbAlc (low group $<5.7 \%, \mathrm{n}=483$; intermediate group $5.7-6.3 \%, \mathrm{n}=$ 512; high group $>6.3 \%, \mathrm{n}=438$ ) were shown in Table 1 . The distribution of HbA1c was shown in Figure 1. As shown in Table 1, patients with the higher HbA1c levels were more likely to be older, female, and have elevated body mass index (BMI) and a prior history of hypertension and dyslipidemia. Meanwhile, the pattern of the inflammation-related biomarkers such as hs-CRP, leucocyte count, fibrinogen and D-dimer were significantly unbalanced among the patients. Additionally, patients with the higher levels of $\mathrm{HbA1c}$ received the more drug administrations and DES implantations.

\section{$\mathrm{HbA1c}$ for predicting the extent of CAD}

There were a statistically significant correlation between the tertiles of plasma $\mathrm{HbA} 1 \mathrm{C}$ and angiographic characteristics (chi-squared for trend, $\mathrm{P}<0.001$, Figure 2). The multivariate logistic regression analysis showed that the plasma HbA1C level was an independent predictor of the presence of $\mathrm{CAD}$ after adjusting for conventional risk factors of CAD (OR = 1.60, 95\% CI: 1.29-1.99, P <0.001, Table 2) . Area under the ROC curves (AUC) analysis also indicated the well discriminatory power of HbA1c levels for the presence of CAD (AUC $=0.67,95 \%$ CI: 0.63-0.71, $\mathrm{P}<0.001$, Figure 3 ).

\section{$\mathrm{HbA1c}$ for predicting the early outcomes}

The population of the present study was followed up for an average of 12 months follow-up (ranged from 14 to 577 days). During follow-up, 133 patients suffered from adverse outcome (Figure 4). There were a significant association between baseline plasma HbA1c levels and incidence of total outcome, revascularization $(\mathrm{P}=0.001$ and $\mathrm{P}=0.016$, respectively), but not for nonfatal $\mathrm{MI}$ or cardiac death $(\mathrm{P}=0.100$ and 0.559 , respectively) during follow-up. The multivariate analysis showed that plasma $\mathrm{HbA1C}$ remained to be an independent predictors of

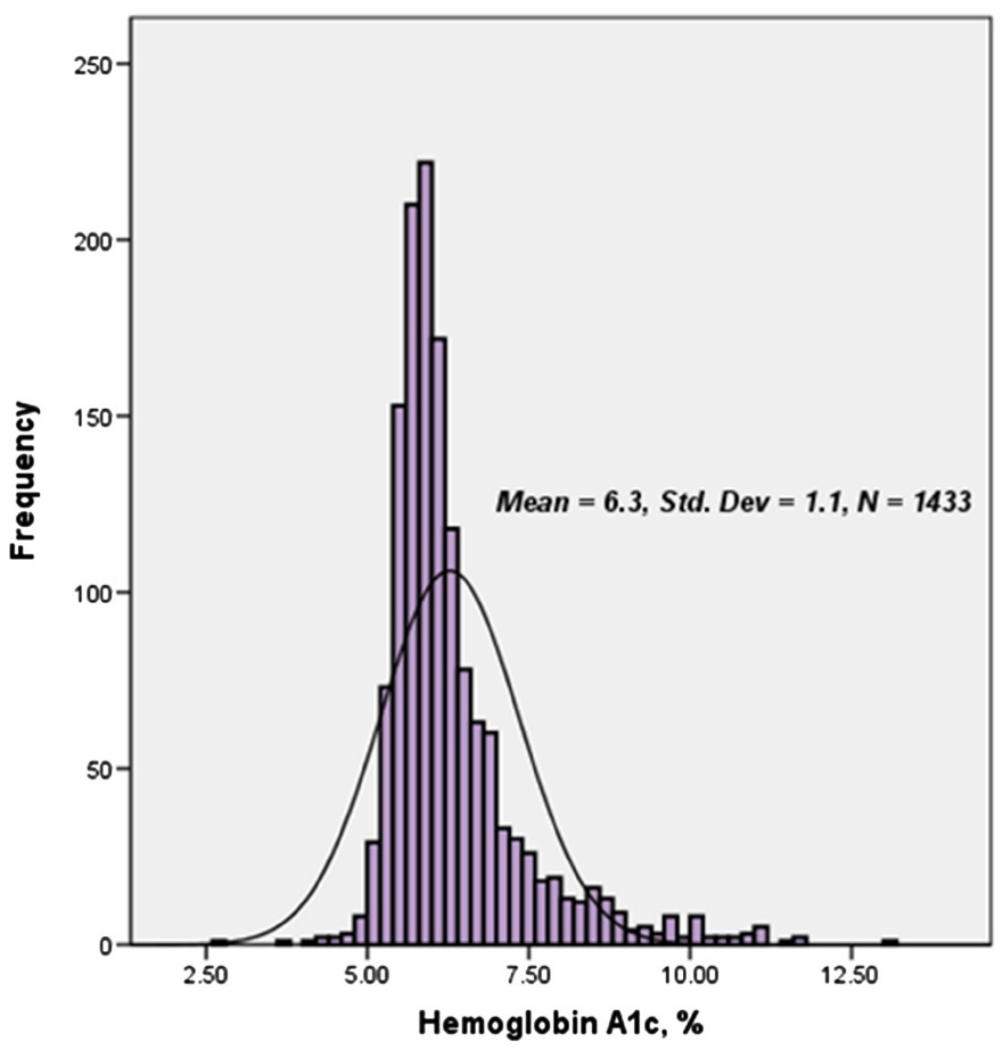

Figure 1 Distribution of baseline serum hemoglobin A1C level in the study population. 


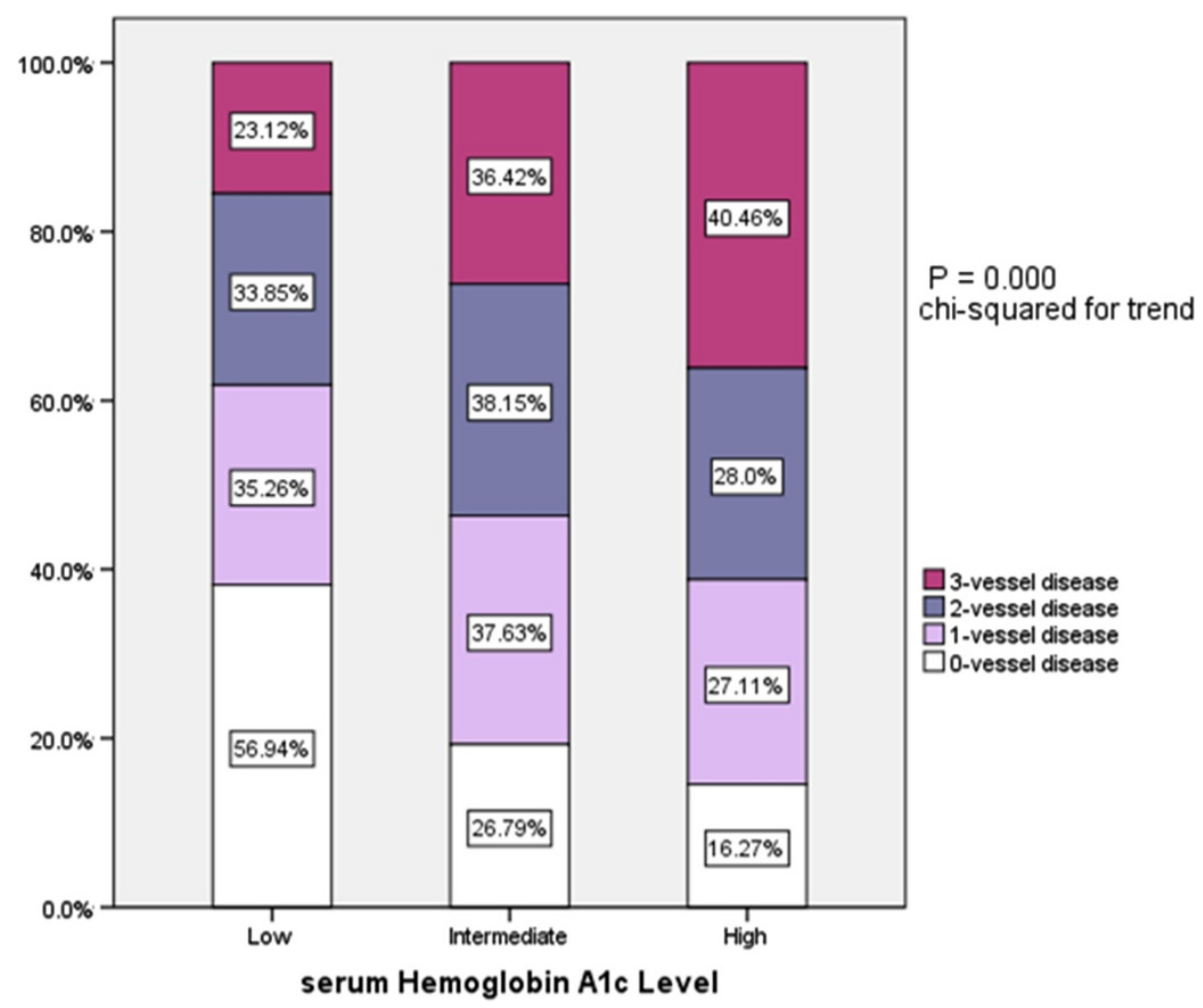

Figure 2 Association of tertiles of serum hemoglobin A1C levels and extent of coronary artery disease.

overall outcome for patients with stable angina $(\mathrm{HR}=1.28$, 95\% CI: $1.12-1.45, \mathrm{P}<0.001)$ except for the family history of CAD and numbers of affected coronary arteries (Table 3 ) after adjusting for all potential confounders including age, gender, cardiovascular risk factors, medicine treatment, DES implantation, baseline lipid profile and other hematological index.

Kaplan-Meier curves for cumulative event-free survival based on the tertiles of baseline HbA1c were presented in Figure 5. As presented in Figure 5, elevated plasma HbA1c (>6.3\%) were generally associated with increased early adverse outcome $(\mathrm{P}<0.001)$. However, subgroup analysis indicated the predictive power of plasma HbA1c was only found in patients with stable angina who had a history of DM $(\mathrm{P}<0.001)$, but not in populations without a history of DM $(\mathrm{P}=0.324)$.

Table 2 Unadjusted and adjusted predictive value of serum hemoglobin A1C levels for coronary artery disease

\begin{tabular}{lcclll}
\hline Variables & \multicolumn{2}{c}{ Unadjusted } & & \multicolumn{2}{c}{ Adjusted } \\
\cline { 2 - 3 } & OR (95\% Cl) & P-value & & OR (95\% Cl) & P-value \\
\hline Gender & $3.06(2.00-4.68)$ & $<0.001$ & & $3.34(2.41-4.64)$ & $<0.001$ \\
Age & $1.04(1.03-1.06)$ & $<0.001$ & & $1.04(1.02-1.06)$ & $<0.001$ \\
Dyslipidemia & $2.26(1.62-3.17)$ & $<0.001$ & & $2.33(1.69-3.22)$ & $<0.001$ \\
Hemoglobin A1C & $1.76(1.32-2.34)$ & $<0.001$ & & $1.60(1.29-1.99)$ & $<0.001$ \\
\hline
\end{tabular}

\section{Discussion}

The present study prospectively investigated the predictive value of plasma $\mathrm{HbA} 1 \mathrm{c}$ for the severity of CAD and mortality in patients with stable CAD. Consistent with previous small sample size studies [24-26], our data also demonstrated that elevated $\mathrm{HbA} 1 \mathrm{C}$ levels significantly conferred to clinical discriminators not only for the presence of CAD, but also for the severity of coronary lesions in patients with CAD. However, both chi-squared for trend and multivariate Cox proportional regression analysis with adjustment for all potential confounders in our study showed the usefulness of HbA1c in predicting the early outcome of the enrolled population. Kaplan-Meier curve for cumulative event-free survival based on the tertiles of baseline plasma HbA1c levels apparently showed that the elevated HbA1c levels $(>6.3 \%)$ were generally associated with increased early adverse outcome. More interestingly, subgroup analysis indicated that the predictive power of plasma HbA1c existed only in patients with DM who presented as stable CAD but not in populations without the history of DM. The results clearly suggested the important role of baseline plasma HbA1c in diabetic patients with CAD.

It has been demonstrated that $\mathrm{DM}$ is a risk for the development of CAD and individuals who had DM will suffer from more intensive atherosclerotic lesions and more cardiovascular events $[29,30]$. Previous studies have 


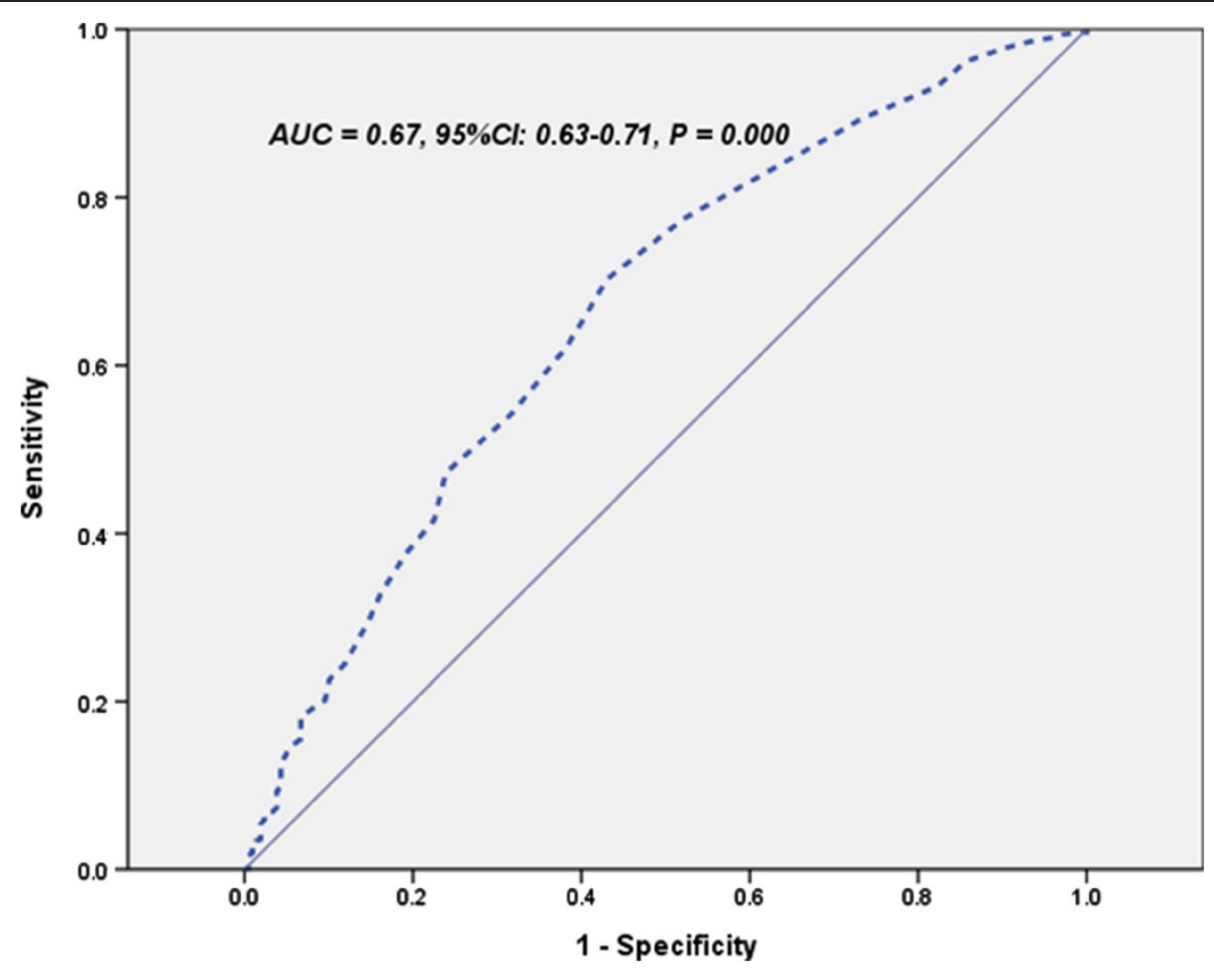

Figure 3 ROC curves showed discriminatory power of serum hemoglobin A1C levels on coronary artery disease.

already suggested an association of high-normal glucose and $\mathrm{HbA1C}$ level with the presence of CAD in a variety of individuals such as in patients with or without diabetes, in asymptomatic persons, even in general population with undiagnosed diabetes [3,22,24,31-33]. However, to the best of our knowledge, there is no data available regarding the role of $\mathrm{HbA} 1 \mathrm{C}$ in the prognostic predictor of patients with DM. In this study, we prospectively enrolled a large cohort of patients who presented as typical angina-like chest pain (stable angina) to evaluating the relationship between $\mathrm{HbA} 1 \mathrm{C}$ and CAD. We found that HbA1C could significantly confer to clinical discriminators not only for the presence of CAD but also for the severity of coronary lesions in these patients. The results analyzed by univariate and multivariate logistic regression models indicated that plasma $\mathrm{HbA1C}$ levels was an independent predictors of

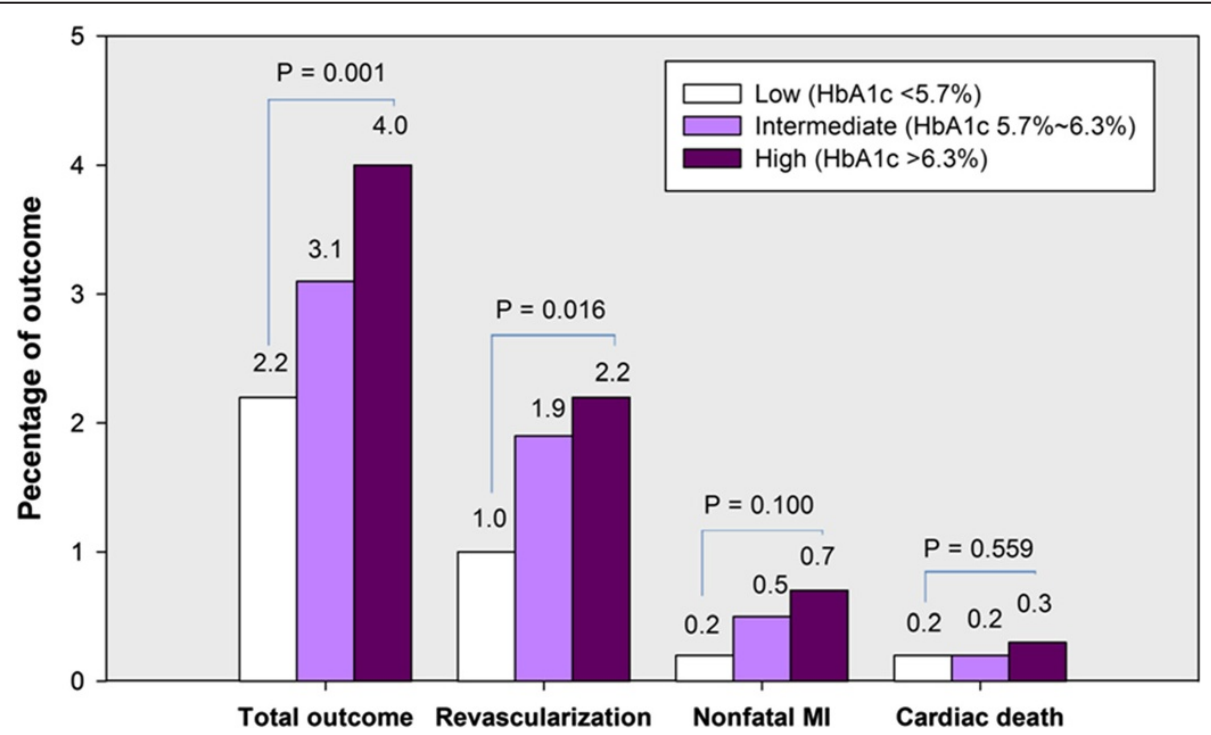

Figure 4 Association of tertiles of serum hemoglobin A1C levels and 12-month outcome. 
Table 3 Unadjusted and adjusted predictive value of serum hemoglobin A1C levels for 12-month total outcome

\begin{tabular}{|c|c|c|c|c|}
\hline \multirow[t]{2}{*}{ Variables } & \multicolumn{2}{|c|}{ Unadjusted } & \multicolumn{2}{|c|}{ Adjusted } \\
\hline & HR $(95 \% \mathrm{Cl})$ & $\overline{P \text {-value }}$ & HR $(95 \% \mathrm{Cl})$ & $\overline{P \text {-value }}$ \\
\hline Family history of CAD & $2.05(1.03-4.06)$ & 0.040 & $1.99(1.01-3.93)$ & 0.046 \\
\hline Numbers of affected coronary arteries & $1.44(1.20-1.73)$ & $<0.001$ & $1.42(1.19-1.69)$ & $<0.001$ \\
\hline Hemoglobin A1C & $1.29(1.07-1.57)$ & 0.008 & $1.28(1.12-1.45)$ & $<0.001$ \\
\hline
\end{tabular}

CAD = coronary artery disease.

the presence of CAD after adjusting for other risk factors of CAD and lipid parameters. AUC evaluation suggested a well discriminatory power of HbA1c for CAD in our population studied.

Indeed, $\mathrm{HbA1C}$ has been proposed as reliable tool for not only diagnosing DM but also identifying individuals at high risk of cardiovascular events with and without DM $[1,19]$. Although accumulating evidence suggested that an elevated $\mathrm{HbA1C}$ level was clearly linked to a poor prognostic outcome in patients with AMI or ACS, even after cardiac surgery or coronary stent implantation, the prognostic value of baseline $\mathrm{HbA} 1 \mathrm{c}$ in patients of stable angina has not been well established $[11,19,20]$. In the present study, we detected that the higher level of plasma HbA1c was relevant to adverse prognosis in patients with stable CAD during an average of 12 month follow-up. Among adverse cardiovascular events, the patients with higher HbA1c were more prone to receive the coronary intervention of revascularizations in agreement with previous studies. Therefore, the present study confirmed and extended previous studies regarding the role of $\mathrm{HbA1c}$ in predicting the severity and early outcome in stable CAD.

The underlying hypothesis of the current results might consisted in that the high levels of HbA1c were not only associated with the long-term disorder of glycolipid metabolism but also connected with low-grade systematic inflammation and atherosclerotic plaques progress [34]. Our data might supported this hypothesis because we found that higher levels of HbA1c in the population studied were clearly associated with the adverse baseline characteristics such as higher cardiovascular risk profile and higher inflammatory biomarkers such as hs-CRP, leukocyte counts, fibrinogen, D-dimer, uric acid and so on. Our data were also in agreement with previous evidence

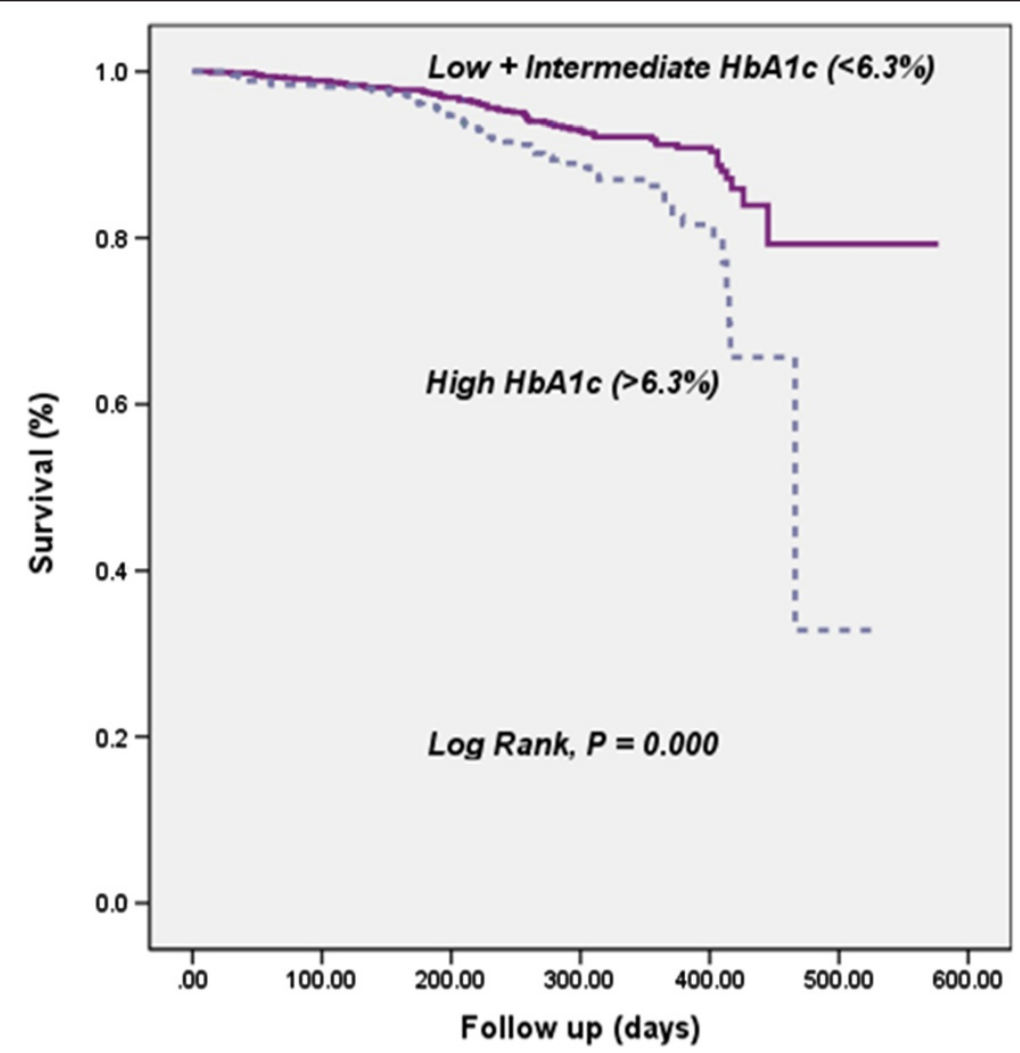

Figure 5 Kaplan-Meier curve for cumulative event-free survival based on tertiles of baseline plasma hemoglobin A1c levels. 
that suggested a correlation between plasma HbA1c with above inflammatory biomarkers, chemical parameters, either alone or combined. These markers or risk factors had a direct role on the progression of atherosclerotic artery disease and adverse cardiovascular events [7,31,35-39]. Moreover, previous studies also suggested that the higher plasma HbA1c might indicate a potential impact of hyperglycemia on the vasculature before the establishments of formal diagnosis for clinically DM and/or overt atherosclerosis disease $[7,40]$. Therefore, as a long half-life protein, HbA1c might be involved in both chronic inflammatory response and acute active phase of ACS, resulting in accelerating the progress and rupture of atherosclerotic lesions.

Summarily, in this prospective, a large cohort, shortterm outcome study, the data clearly suggested that high level of plasma $\mathrm{HbA1C}(>6.3 \%)$ was an independent predictor for the presence and severity of CAD as well as the early outcome of patients with stable angina. Long-term follow-up may be needed for further revealing more information regarding the role of $\mathrm{HbA1C}$ in diabetic patients with stable CAD.

\section{Abbreviations}

HbA1c: Hemoglobin A1C; CAD: Coronary artery disease; DM: Diabetes mellitus.

\section{Competing interests}

The authors declare no conflicts of interests.

\section{Authors' contributions}

L-FH wrote the manuscript. J-JL conceived and designed the study, reviewed and edited of manuscript. L-FH and X-LL collected and analyzed the data. Y-LG, S-HL, C-GZ, PQ, R-XX and N-QW searched the literatures and collected data. All authors read and approved the final manuscript.

\section{Acknowledgments}

We thank the staff and participants of this study for their important contributions for this study. This article is partly supported by National Natural Scientific Foundation (81070171, 81241121), Specialized Research Fund for the Doctoral Program of Higher Education of China

(20111106110013), Fund of Capital Special Foundation of Clinical Application Research (Z121107001012015), Capital Health Development Fund (2011400302), and Beijing Natural Science Foundation (7131014) awarded to Dr. Jian-Jun Li, MD, PhD.

\section{Author details}

'Division of Dyslipidemia, State Key Laboratory of Cardiovascular Disease, Fu Wai Hospital, National Center for Cardiovascular Diseases, Chinese Academy of Medical Sciences, Peking Union Medical College, Beijing 100037, China. ${ }^{2}$ Divison of Cardiology, Guangci Hospital affiliated Medical College of Wuhan University \& the Fifth Hospital of Wuhan, Wuhan 430050, China.

Received: 16 February 2014 Accepted: 13 May 2014

Published: 29 May 2014

\section{References}

1. Sacks DB, Arnold M, Bakris GL, Bruns DE, Horvath AR, Kirkman MS, Lernmark A, Metzger BE, Nathan DM: Guidelines and recommendations for laboratory analysis in the diagnosis and management of diabetes mellitus. Diabetes Care 2011, 34:e61-e99.

2. Gorus F, Mathieu C, Gerlo E: How should HbA1c measurements be reported? Diabetologia 2006, 49:7-10.
3. Su G, Mi S, Tao H, Li Z, Yang H, Zheng H, Zhou Y, Ma C: Association of glycemic variability and the presence and severity of coronary artery disease in patients with type 2 diabetes. Cardiovasc Diabetol 2011, 10:19.

4. Lorenzo C, Wagenknecht LE, Hanley AJ, Rewers MJ, Karter AJ, Haffner SM: A1C Between 5.7 and $6.4 \%$ as a Marker for Identifying Pre-Diabetes, Insulin Sensitivity and Secretion, and Cardiovascular Risk Factors The Insulin Resistance Atherosclerosis Study (IRAS). Diabetes Care 2010, 33:2104-2109.

5. Selvin E, Steffes MW, Gregg E, Brancati FL, Coresh J: Performance of A1C for the classification and prediction of diabetes. Diabetes Care 2011, 34:84-89.

6. Gustavsson CG, Agardh CD: Markers of inflammation in patients with coronary artery disease are also associated with glycosylated haemoglobin A1c within the normal range. Eur Heart J 2004, 25:2120-2124.

7. Rogowski O, Shapira I, Peretz H, Berliner S: Glycohaemoglobin as a determinant of increased fibrinogen concentrations and low-grade inflammation in apparently healthy nondiabetic individuals. Clin Endocrinol (Oxf) 2008, 68:182-189.

8. Knapik P, Ciesla D, Filipiak K, Knapik M, Zembala M: Prevalence and clinical significance of elevated preoperative glycosylated hemoglobin in diabetic patients scheduled for coronary artery surgery. Eur J Cardiothorac Surg 2011, 39:484-489.

9. Zhao X, Chang Mei H, Chen L, Jiang L, He M, Chen J, Hu Z, Ye H, Hu H, Zhou L, Li Y, Hu R: An increased level of haemoglobin A1C predicts a poorer clinical outcome in patients with acute pancreatitis. Clin Endocrinol (Oxf) 2012, 77:241-245.

10. Bonora E, Kiechl S, Mayr A, Zoppini G, Targher G, Bonadonna RC, Willeit J: High-normal HbA1c is a strong predictor of type 2 diabetes in the general population. Diabetes Care 2011, 34:1038-1040.

11. Gustafsson I, Kistorp CN, James MK, Faber JO, Dickstein K, Hildebrandt PR: Unrecognized glycometabolic disturbance as measured by hemoglobin A1c is associated with a poor outcome after acute myocardial infarction. Am Heart J 2007, 154:470-476.

12. Cicek G, Uyarel H, Ergelen M, Ayhan E, Abanonu GB, Eren M, Gibson CM: Hemoglobin A1c as a prognostic marker in patients undergoing primary angioplasty for acute myocardial infarction. Coron Artery Dis 2011, 22:131-137.

13. Su G, Mi SH, Tao H, Li Z, Yang HX, Zheng H, Zhou Y, Tian L: Impact of admission glycemic variability, glucose, and glycosylated hemoglobin on major adverse cardiac events after acute myocardial infarction. Diabetes Care 2013, 36:1026-1032.

14. Cederberg H, Saukkonen T, Laakso M, Jokelainen J, Härkönen P, Timonen M, Keinänen-Kiukaanniemi S, Rajala U: Postchallenge Glucose, A1C, and Fasting Glucose as Predictors of Type 2 Diabetes and Cardiovascular Disease A 10-year prospective cohort study. Diabetes Care 2010, 33:2077-2083.

15. Rivera JJ, Choi EK, Yoon YE, Chun EJ, Choi SI, Nasir K, Brancati FL, Blumenthal RS, Chang HJ: Association between increasing levels of hemoglobin A1c and coronary atherosclerosis in asymptomatic individuals without diabetes mellitus. Coron Artery Dis 2010, 21:157-163.

16. Tekumit H, Cenal AR, Polat A, Uzun K, Tataroglu C, Akinci E: Diagnostic value of hemoglobin A1c and fasting plasma glucose levels in coronary artery bypass grafting patients with undiagnosed diabetes mellitus. Ann Thorac Surg 2010, 89:1482-1487.

17. Kassaian SE, Goodarzynejad H, Boroumand MA, Salarifar M, Masoudkabir F, Mohajeri-Tehrani MR, Pourhoseini H, Sadeghian S, Ramezanpour N, Alidoosti M, Hakki E, Saadat S, Nematipour E: Glycosylated hemoglobin (HbA1c) levels and clinical outcomes in diabetic patients following coronary artery stenting. Cardiovasc Diabetol 2012, 11:82.

18. Timmer JR, Hoekstra M, Nijsten MW, van der Horst IC, Ottervanger JP, Slingerland RJ, Dambrink JH, Bilo HJ, Zijlstra F, Hof AW V 't: Prognostic value of admission glycosylated hemoglobin and glucose in nondiabetic patients with ST-segment-elevation myocardial infarction treated with percutaneous coronary intervention. Circulation 2011, 124:704-711.

19. Liu Y, Yang YM, Zhu J, Tan HQ, Liang Y, Li JD: Prognostic significance of hemoglobin A1c level in patients hospitalized with coronary artery disease. A systematic review and meta-analysis. Cardiovasc Diabetol 2011, 10:98.

20. Shah AD, Nicholas O, Timmis AD, Feder G, Abrams KR, Chen R, Hingorani $A D$, Hemingway $H$ : Threshold haemoglobin levels and the prognosis of stable coronary disease: two new cohorts and a systematic review and meta-analysis. PLoS Med 2011, 8:e1000439.

21. Lemesle G, Bonello L, De Labriolle A, Maluenda G, Syed Al, Collins SD, Ben-Dor I, Torguson R, Kaneshige K, Xue Z, Suddath WO, Satler LF, Kent KM, 
Lindsay J, Pichard AD, Waksman R: Prognostic value of hemoglobin A1C levels in patients with diabetes mellitus undergoing percutaneous coronary intervention with stent implantation. Am J Cardiol 2009, 104:41-45.

22. Ravipati G, Aronow WS, Ahn C, Sujata K, Saulle LN, Weiss MB: Association of hemoglobin $A(1 c)$ level with the severity of coronary artery disease in patients with diabetes mellitus. Am J Cardiol 2006, 97:968-969.

23. Shen Y, Pu L, Lu L, Zhang Q, Zhang RY, Shen WF: Glycated albumin is superior to hemoglobin A1c for evaluating the presence and severity of coronary artery disease in type 2 diabetic patients. Cardiology 2012, 123:84-90.

24. Saleem T, Mohammad KH, Abdel-Fattah MM, Abbasi AH: Association of glycosylated haemoglobin level and diabetes mellitus duration with the severity of coronary artery disease. Diab Vasc Dis Res 2008, 5:184-189.

25. Konstantinou DM, Chatzizisis YS, Louridas GE, Parcharidis GE, Giannoglou GD: Non-diabetic hyperglycaemia correlates with angiographic coronary artery disease prevalence and severity. Diabetes Metab 2010, 36:402-408.

26. Berry C, Noble S, Gregoire JC, Ibrahim R, Levesquie S, Lavoie MA, L'Allier PL, Tardif JC: Glycaemic status influences the nature and severity of coronary artery disease. Diabetologia 2010, 53:652-658.

27. Chobanian AV, Bakris GL, Black HR, Cushman WC, Green LA, Izzo JL Jr, Jones DW, Materson BJ, Oparil S, Wright JT Jr, Roccella EJ: Seventh report of the Joint National Committee on Prevention, Detection, Evaluation, and Treatment of High Blood Pressure. Hypertension 2003, 42:1206-1252.

28. World Health Organization: Definition and diagnosis of diabetes mellitus and intermediate hyperglycaemia: Report of a WHO/IDF consultation. Geneva: WHO Document Production Services; 2006.

29. Beckman JA, Creager MA, Libby P: Diabetes and atherosclerosis: epidemiology, pathophysiology, and management. JAMA 2002, 287:2570-2581.

30. Emerging Risk Factors C, Sarwar N, Gao P, Seshasai SR, Gobin R, Kaptoge S, Di Angelantonio E, Ingelsson E, Lawlor DA, Selvin E, Stampfer M, Stehouwer CD, Lewington S, Pennells L, Thompson A, Sattar N, White IR, Ray KK, Danesh J: Diabetes mellitus, fasting blood glucose concentration, and risk of vascular disease: a collaborative meta-analysis of 102 prospective studies. Lancet 2010, 375:2215-2222.

31. Pacilli A, De Cosmo S, Trischitta V, Bacci S: Role of relationship between $\mathrm{HbA1C}$, fibrinogen and HDL-cholesterol on cardiovascular disease in patients with type 2 diabetes mellitus. Atherosclerosis 2013, 228:247-248.

32. Prince $C T$, Becker DJ, Costacou T, Miller RG, Orchard TJ: Changes in glycaemic control and risk of coronary artery disease in type 1 diabetes mellitus: findings from the Pittsburgh Epidemiology of Diabetes Complications Study (EDC). Diabetologia 2007, 50:2280-2288.

33. Ohashi K, Ouchi N, Kihara S, Funahashi T, Nakamura T, Sumitsuji S, Kawamoto T, Matsumoto S, Nagaretani H, Kumada M, Okamoto $Y$, Nishizawa H, Kishida K, Maeda N, Hiraoka H, Iwashima Y, Ishikawa K, Ohishi M, Katsuya T, Rakugi H, Ogihara T, Matsuzawa Y: Adiponectin I164T mutation is associated with the metabolic syndrome and coronary artery disease. J Am Coll Cardiol 2004, 43:1195-1200.

34. Daida H, Takayama T, Hiro T, Yamagishi M, Hirayama A, Saito S, Yamaguchi T, Matsuzaki M: High HbA1c levels correlate with reduced plaque regression during statin treatment in patients with stable coronary artery disease: results of the coronary atherosclerosis study measuring effects of rosuvastatin using intravascular ultrasound in Japanese subjects (COSMOS). Cardiovasc Diabetol 2012, 11:87.

35. Piedrola G, Novo E, Escobar F, Garcia-Robles R: White blood cell count and insulin resistance in patients with coronary artery disease. Ann Endocrinol (Paris) 2001, 62:7-10.

36. Gui MH, Hong J, Lu AK, Chen Y, Shen WF, Li XY, Ning G: High sensitive C-reactive protein, adiponectin, and urine albumin excretion rate in Chinese coronary artery disease patients with different glucose tolerance status. Chin Med J (Engl) 2008, 121:2509-2516.

37. McBane RD 2nd, Hardison RM, Sobel BE, Group BDS: Comparison of plasminogen activator inhibitor-1, tissue type plasminogen activator antigen, fibrinogen, and D-dimer levels in various age decades in patients with type 2 diabetes mellitus and stable coronary artery disease (from the BARI 2D trial). Am J Cardiol 2010, 105:17-24.

38. Ruggiero C, Cherubini A, Ble A, Bos AJ, Maggio M, Dixit VD, Lauretani F, Bandinelli S, Senin U, Ferrucci L: Uric acid and inflammatory markers. Eur Heart J 2006, 27:1174-1181

39. Goliasch G, Kleber ME, Richter B, Plischke M, Hoke M, Haschemi A, Marculescu R, Endler G, Grammer TB, Pilz S, Tomaschitz A, Silbernagel G,
Maurer G, Wagner O, Huber K, Marz W, Mannhalter C, Niessner A: Routinely available biomarkers improve prediction of long-term mortality in stable coronary artery disease: the Vienna and Ludwigshafen Coronary Artery Disease (VILCAD) risk score. Eur Heart J 2012, 33:2282-2289.

40. Davidson MH: Cardiovascular risk factors in a patient with diabetes mellitus and coronary artery disease: therapeutic approaches to improve outcomes: perspectives of a preventive cardiologist. Am J Cardiol 2012, 110:43B-49B.

doi:10.1186/1476-511X-13-89

Cite this article as: Hong et al:: Glycosylated hemoglobin A1c as a marker predicting the severity of coronary artery disease and early outcome in patients with stable angina. Lipids in Health and Disease 2014 13:89.

\section{Submit your next manuscript to BioMed Central and take full advantage of:}

- Convenient online submission

- Thorough peer review

- No space constraints or color figure charges

- Immediate publication on acceptance

- Inclusion in PubMed, CAS, Scopus and Google Scholar

- Research which is freely available for redistribution 